\title{
Prostatic disorders in acromegalic patients experience of a Brazilian center
}

\author{
Lívia L. Corrêa, Giovanna A. Balarini Lima, Suzana A. Cavallieri, Luiz Carlos D. de Miranda, Mônica \\ R. Gadelha
}

Service of Endocrinology, University Hospital Clementino Fraga Filho (HUCFF), Federal University of Rio de Janeiro (UFRJ) (LLC, GABL, MRG); Department of Urology, University Hospital Clementino Fraga Filho (HUCFF), Federal University of Rio de Janeiro (UFRJ) (LCDM) and Labs D'Or Laboratory and Imaging (SAC), Rio de Janeiro, RJ, Brazil

\section{ABSTRACT}

Introduction: Published data suggest that patients with acromegaly have an increased prevalence of prostate disorders.

Objective: To evaluate prostatic disorders in acromegalic patients comparing these results after one year of treatment of acromegaly and with a group of healthy men.

Materials and Methods: This study was composed of two parts: sectional study comparing patients with healthy controls (baseline) and prospective, longitudinal study (at baseline and after one year of treatment). Forty acromegalic patients were enrolled and evaluated at baseline and after one year with the application of international prostatic symptoms score (IPSS), digital rectal examination, measurements of growth hormone (GH), insulin-like growth factor-I (IGF-I), insulin-like growth factor-binding protein-3 (IGFBP-3), sex hormone-binding globulin (SHBG), prolactin, luteinizing hormone (LH), follicle-stimulating hormone (FSH), total testosterone, total and free prostate-specific antigen (PSA) levels and prostate ultrasonography (US). Thirty healthy men were selected as control group.

Results: We stratified patients and controls according to age, considering 40 years-old as cut off. Healthy controls under 40 had IPSS values lower than acromegalic patients. When considering only older patients and controls prostate hyperplasia and structural abnormalities were more frequent in acromegalics. After one year of treatment there was significant decrease in GH, IGF-I and prostate volume in acromegalics over 40 years-old. Conclusions: Acromegalics under 40 have more urinary symptoms according to IPSS and above 40 years-old higher frequency of structural changes and increased prostate volume than healthy men. Significant reduction of GH and IGF-I levels during treatment of acromegaly leads to decrease in the prostate volume.

\section{ARTICLE INFO}

\section{Key words:}

Acromegaly; BPH;

Prostate-specific antigen;

Prostate

Int Braz J Urol. 2013; 39: 393-401

Submitted for publication:

February 28, 2012

Accepted after revision:

December 14, 2012

\section{INTRODUCTION}

Acromegaly is a rare disease caused by GH hyper secretion $(1,2)$. It is well known that GH promotes a stimulatory effect on IGF-I and IGFBP-3. IGF-I stimulates cell proliferation (3), however, IGFBP-3 stimulates apoptosis (4). Therefore, it is not well established whether acromegaly is associated or not with increased relative risk for cancer development.

Several epidemiologic studies have suggested that high-normal serum IGF-I levels may 
be concordant with a higher risk of prostate cancer in the general population, and that high-normal serum IGFBP-3 levels are concordant with a lower risk (5-8). Published data suggest that the relationship between prostatic carcinoma and acromegaly is infrequent (9).

Patients with acromegaly have an increased prevalence of prostatic disorders compared to age-matched healthy subjects. Increased size of the whole prostate, together with an elevated incidence of other structural changes, such as nodules, cysts, and calcifications were shown in a large proportion of patients $(10,11)$. The presence of an enlarged prostate in acromegalic patients under 40 years suggests a possible role of GH-IGF-I axis on this gland growth $(10,11)$. Only two studies evaluated the effects of acromegaly treatment on prostate volume (PV), and demonstrated that well controlled patients presented significant reduction in PV after treatment of acromegaly $(10,12)$.

The IPSS is a symptom index for benign prostatic hyperplasia (BPH), developed and validated by a multidisciplinary measurement committee of the American Urological Association (AUA) (13). The IPSS is widely used to evaluate the severity of urinary symptoms $(14,15)$. Until today, there is no report of the use of IPSS in the evaluation of acromegalic patients.

In a recent guideline for acromegaly management (16) there was no information about the BPH evaluation. The aim of this study was to evaluate the prostate of acromegalic patients through digital rectal examination, transrectal US and IPSS, comparing these results with a group of healthy men, above and below 40 years, and after one year of acromegaly treatment.

\section{MATERIALS AND METHODS}

\section{Patients}

Forty acromegalic patients, aged $45.2 \pm 11.3$ years (24-69 years), were recruited from the outpatient endocrinology clinic of the University Hospital Clementino Fraga Filho - HUCFF, of the Federal University of Rio de Janeiro - UFRJ, over a 24-month period. The diagnosis of acromegaly was based on the following criteria: 1) a lack of suppression of GH to below $1 \mathrm{ng} / \mathrm{mL}$ after oral administration of $75 \mathrm{~g}$ glucose or 2) high serum IGF-I levels. Reasons for ineligibility included patients with previous treatment of prostate cancer or BPH. All subjects entered the study after obtaining written informed consent according to a protocol approved by the Ethics Committee of HUCFF.

At baseline, 36 patients had active disease (10 were de novo patients) and four had acromegaly cure or control for less than one year before the inclusion in this study. Twenty-six patients were previously submitted to surgery, nine to radiotherapy and 25 to medical treatment with octreotide LAR and/or cabergoline. Hypogonadism, based on low testosterone levels, was present in 27 (67.5\%) patients. Seventeen of these patients were not receiving testosterone as replacement therapy because of severe sleep apnea.

As control group, thirty healthy and education-matched men were included. Fourteen of them were less than 40 years-old and were paired to the 14 acromegalic patients younger than 40 years. The other 16 were proportionally age-matched with the 26 acromegalics older than 40 years-old.

\section{Study design}

This study was composed of two parts: a) sectional study comparing patients (at baseline) with healthy controls; b) prospective, longitudinal study (at baseline and after one year of treatment). The study protocol included application of IPSS, digital rectal examination, measurements of GH, IGF-I, IGFBP-3, SHBG, prolactin, LH, FSH, total testosterone, total and free PSA levels and transrectal US, both at baseline and after one year of treatment for patients and on baseline for controls. The free testosterone and the bioavailable testosterone were calculated according to the Vermeulen's formula (17).

\section{Urologic evaluation}

The IPSS is a survey composed of seven questions related to incomplete bladder emptying, urinary frequency, intermittency, urgency, weak stream, straining and nocturia. To each answer is attributed a value in scale ( $0-5$ points), to a maximum of 35 points. A total score of 0-7 indicates mildly symptomatic; 8-19 moderately symptomatic; 20-35 severely symptomatic patients (13). This survey was validated to the Portuguese language in 1999 (18). 
The digital rectal examination was performed by the same urologist (LCDM).

\section{Hormone assays}

Serum GH, IGF-I, IGFBP-3, SHBG, prolactin, $\mathrm{LH}, \mathrm{FSH}$ and total testosterone levels were determined by chemiluminescense immunometric assays. Total and free PSA serum levels were measured by electrochemiluminescense assay.

The low detection limit of GH by the Immulite 2000 kit (DPC- Diagnostic Products Corporation, Los Angeles, CA) is $0.01 \mathrm{ng} / \mathrm{mL}$ and its linear working range is $0.01-40 \mathrm{ng} / \mathrm{mL}$. Standards are calibrated against the International Standard WHO 98/574. The intra-assay CVs at the respective concentrations of 1.7, 7.8 and $31.0 \mathrm{ng} / \mathrm{mL}$ are 5.3\%, 6.0\% and 6.5\%, while the inter-assay CVs at 3.0, 9.3 and $18.0 \mathrm{ng} /$ $\mathrm{mL}$ are $5.7 \%, 6.2 \%$ and $6.1 \%$, respectively. The low detection limit of IGF-I measured by Immulite 2000 kit DPC is $20 \mathrm{ng} / \mathrm{mL}$ and the intra and inter-assay CVs are 3.6 and 6.6\%, respectively. The standards are calibrated against the first International Reference Reagent WHO 87/518 and IGF-I was expressed in mass units and age-related standard deviation scores (SD-scores).

All serum samples were collected in the early morning after an eight-hour fasting period.

\section{Transrectal US}

Transrectal US was performed with a HDI 11XE, Phillips, 2008, using a 5.0-7.5 MHz transducer by the same radiologist (SAC). The prostate examination included the anterior-posterior (AP), transversal (T) and longitudinal (L) diameters, the morphology of boundaries, texture, the occurrence of calcifications and/or nodules, and the evaluation of seminal vesicles and bladder. Prostate volume was calculated by the elliptical shape volume formula $(\pi / 6 \mathrm{x}$ APD $\mathrm{x}$ TD $x$ LD). Prostate hyperplasia was defined as a PV exceeding $30 \mathrm{~mL}$ (19-21).

\section{Statistical analysis}

Analyses were performed by SAS System (version 6.11; SAS Institute North Caroline). The results were expressed as median (min-max). Comparisons between categorical variables were done by $\chi^{2} 2$ test and between numerical variables were carried out using the Mann Whitney test. Comparisons between related samples were done by Wilcoxon test. McNemar's test was used to compare paired proportions. Correlations were sought by calculating the Spearman's rank correlation coefficient. P values $<0.05$ were considered statistically significant.

\section{RESULTS}

Comparison between acromegalic patients and control group under 40 years at baseline

Because it is well established that prostate enlargement starts approximately at the age of 40 $(22,23)$, we stratified patients and controls according to age, considering 40 years-old as cut off. When considering only younger patients and controls (Table-1), the acromegalics presented high levels of GH (4.96 vs $0.05, p=0.0001)$, IGF-I (914.50 vs 183.00 , $\mathrm{p}=0.0002$ ), IGFBP-3 (6.96 vs $4.36, \mathrm{p}=0.0008$ ) and IPSS (2.00 vs $0.00, p=0.003)$ and presented low levels of LH (2.07 vs $4.85, \mathrm{p}=0.0009)$, total testosterone (135.00 vs $567.50, \mathrm{p}=0.0001)$, free testosterone (4.17 vs $13.40, \mathrm{p}=0.0001$ ), bioavailable testosterone ( 97.70 vs $314.00, p=0.0001)$ and SHBG (11.00 vs $25.20, p=0.0005$ ). The mean PV was not different between these two groups (18.50 vs 15.00 , $\mathrm{p}=0.10)$.

Prostate hyperplasia was not found in patients or controls under 40. Structural abnormalities found at US were: calcifications in one patient and one control (7\% vs 7\%, $p=1.0)$ and hyperechogenic foci suggesting corpora amylacea in 4 patients and 3 controls (28.6\% vs $21.4 \%, p=1.0)$.

Comparison between acromegalic patients and control group above 40 years at baseline

When considering only patients and controls $\geq 40$ years-old (Table- 2 ), the acromegalics presented higher levels of GH (4.92 vs $0.05, p=0.0001$ ), IGF-I (466.00 vs $142.00, p=0.0001$ ), IGFBP-3 (5.65 vs $3.93, p=0.0005)$ and PV (28.50 vs 20.50, $p=0.048)$ and presented lower levels of LH (1.81 vs 3.30, $\mathrm{p}=$ 0.0002), total testosterone ( 256.50 vs $542.00, \mathrm{p}=$ 0.004), free testosterone (5.96 vs $10.95, \mathrm{p}=0.002$ ), bioavailable testosterone ( 139.50 vs $256.50, \mathrm{p}=$ $0.002)$ and SHBG (20.40 vs 33.00, $\mathrm{p}=0.034)$.

Prostate hyperplasia was found in 12 patients and 2 controls. The frequency of BPH was 
Table 1 - Characteristics of acromegalic patients at baseline and control group ( $<40$ years-old).

\begin{tabular}{lccccc}
\hline & \multicolumn{2}{c}{$\begin{array}{c}\text { Acromegalic patients } \\
(\mathrm{n}=14)\end{array}$} & \multicolumn{2}{c}{$\begin{array}{c}\text { Control group } \\
(\mathrm{n}=14)\end{array}$} \\
& Median & Min-Max & Median & Min-Max & p value \\
\hline Age (years) & 34.00 & $24.00-39.00$ & 33.50 & $24.00-38.00$ & 0.63 \\
GH (ng/mL) & 4.96 & $0.23-40.00$ & 0.05 & $0.04-2.10$ & 0.0001 \\
IGF-I (ng/mL) & 914.50 & $114.00-1158.00$ & 183.00 & $128.00-282.00$ & 0.0002 \\
IGFBP-3 (mcg/mL) & 6.96 & $1.96-10.50$ & 4.36 & $2.50-5.25$ & 0.0008 \\
PRL (ng/mL) & 9.00 & $0.50-61.00$ & 9.47 & $4.07-29.10$ & 0.85 \\
FSH (mUl/mL) & 4.86 & $0.10-14.70$ & 4.23 & $1.20-7.63$ & 0.93 \\
LH (mUl/mL) & 2.07 & $0.10-6.97$ & 4.85 & $1.60-15.00$ & 0.0009 \\
Total testosterone (ng/dL) & 135.00 & $20.00-289.00$ & 567.50 & $365.00-1094.00$ & 0.0001 \\
Free testosterone (ng/dL) & 4.17 & $0.73-7.44$ & 13.40 & $8.70-30.50$ & 0.0001 \\
Bioavailable testosterone (ng/dL) & 97.70 & $17.10-174.00$ & 314.00 & $204.00-715.00$ & 0.0001 \\
SHBG (nmol/L) & 11.00 & $3.60-35.90$ & 25.20 & $8.20-47.00$ & 0.0005 \\
Total PSA (ng/mL) & 0.65 & $0.04-1.65$ & 0.65 & $0.34-2.17$ & 0.71 \\
Free PSA (ng/mL) & 0.12 & $0.05-0.38$ & 0.18 & $0.07-0.33$ & 0.45 \\
IPSS & 2.00 & $0.00-12.00$ & 0.00 & $0.00-2.00$ & 0.003 \\
\hline Prostate volume $(\mathrm{mL})$ & 18.50 & $12.00-28.00$ & 15.00 & $12.00-19.00$ & 0.10 \\
\hline
\end{tabular}

Normal Values: GH (0.06-5 ng/mL), IGF-I (116-358, 117-329, 115-307, 109-284, 101-267, 94-252, 87-238, 81-225, 75-212, 69-200 ng/mL for patients aged 21-25, 26-30, 31-35, 36-40, 41-45, 46-50, 51-55, 56-60, 61-65 and 66-70, respectively), IGFBP-3 (3.4-7.8, 3.5-7.6, 3.5-7.0, 3.4-6.7, 3.4-6.6, 3.3-6.7, 3.4-6.8, 3.4-6.9, 3.2-6.6, 3.0-6.2 mcg/mL for patients aged 21-25, 26-30, 31-35, 36-40, 41-45, 46-50, 51-55, 56-60, 61-65 and 66-70, respectively), PRL (2.1-17.7 ng/mL), FSH (1.4-18.1 mUl/mL), LH (1.5-9.3 mUl/mL), total testosterone (241-827 ng/dL), free testosterone (4.7-23 ng/dL), bioavailable testosterone (140-400 ng/dL), SHBG (13-71 nmol/L), total PSA (less than $4 \mathrm{ng} / \mathrm{mL}$ ), free PSA (less than $0.92 \mathrm{ng} / \mathrm{mL}$ ), IPSS (0-35), prostate volume (less than $30 \mathrm{~mL}$ ).

significantly higher in the acromegalic population when compared with the control group (46.15\% vs $12.50 \%, p=0.015)$. Structural abnormalities were also more frequent in acromegalics: calcifications in 11 patients and one control (42.31\% vs 6.25\%, p = 0.018 ) and hyperechogenic foci suggesting corpora amylacea in 18 patients and 5 controls $(69.23 \%$ vs $31.25 \%, p=0.036)$. A uthricular cyst of $0.4 \mathrm{~cm}$ was found in one patient.
Comparison of the acromegalic patients under 40 years at baseline and after one year of treatment

The main characteristics of the acromegalic population under 40 years before and after treatment are presented in Table-3.

After one year of treatment, there was a significant reduction in GH (4.96 vs 3.28, $p=0.011$ ). Biochemical control of acromegaly, based on random $\mathrm{GH}<1 \mathrm{ng} / \mathrm{mL}$ and normal IGF-I (24), was achieved 
Table 2 - Characteristics of acromegalic patients at baseline and control group ( $\geq \mathbf{4 0}$ years-old).

\begin{tabular}{|c|c|c|c|c|c|}
\hline & \multicolumn{2}{|c|}{$\begin{array}{l}\text { Acromegalic patients } \\
\qquad(\mathrm{n}=26)\end{array}$} & \multicolumn{2}{|c|}{$\begin{array}{l}\text { Control group } \\
\qquad(\mathrm{n}=16)\end{array}$} & \multirow[b]{2}{*}{$\mathrm{p}$ value } \\
\hline & Median & Min-max & Median & Min-Max & \\
\hline Age (years) & 50.00 & $42.00-69.00$ & 52.00 & $40.00-69.00$ & 0.74 \\
\hline $\mathrm{GH}(\mathrm{ng} / \mathrm{mL})$ & 4.92 & $0.28-68.90$ & 0.05 & $0.05-1.70$ & 0.0001 \\
\hline IGF-I (ng/mL) & 466.00 & $104.00-1600.00$ & 142.00 & $83.20-206.00$ & 0.0001 \\
\hline IGFBP-3 (mcg/mL) & 5.65 & $3.24-11.90$ & 3.93 & $2.32-6.13$ & 0.0005 \\
\hline $\mathrm{PRL}(\mathrm{ng} / \mathrm{mL})$ & 5.80 & $0.50-86.39$ & 7.43 & $3.70-14.40$ & 0.043 \\
\hline $\mathrm{FSH}(\mathrm{mUl} / \mathrm{mL})$ & 4.10 & $0.10-15.40$ & 4.48 & $2.15-12.30$ & 0.58 \\
\hline $\mathrm{LH}(\mathrm{mUI} / \mathrm{mL})$ & 1.81 & $0.10-4.68$ & 3.30 & $2.16-6.10$ & 0.0002 \\
\hline Total testosterone $(\mathrm{ng} / \mathrm{dL})$ & 256.50 & $20.00-1688.00$ & 542.00 & $206.00-790.00$ & 0.004 \\
\hline Free testosterone $(\mathrm{ng} / \mathrm{dL})$ & 5.96 & $0.23-66.90$ & 10.95 & $5.10-15.20$ & 0.002 \\
\hline Bioavailable testosterone $(\mathrm{ng} / \mathrm{dL})$ & 139.50 & $5.39-1570.00$ & 256.50 & $120.00-356.00$ & 0.002 \\
\hline SHBG (nmol/L) & 20.40 & $6.00-79.50$ & 33.00 & $12.60-54.00$ & 0.034 \\
\hline Total PSA (ng/mL) & 0.63 & $0.04-2.50$ & 0.93 & $0.31-2.80$ & 0.18 \\
\hline Free PSA (ng/mL) & 0.15 & $0.04-0.57$ & 0.27 & $0.06-0.55$ & 0.066 \\
\hline IPSS & 4.50 & $0.00-21.00$ & 4.00 & $0.00-16.00$ & 0.19 \\
\hline Prostate volume $(\mathrm{mL})$ & 28.50 & $10.00-84.00$ & 20.50 & $11.00-40.00$ & 0.048 \\
\hline
\end{tabular}

Normal Values: GH (0.06-5 ng/mL), IGF-I (116-358, 117-329, 115-307, 109-284, 101-267, 94-252, 87-238, 81-225, 75-212, 69-200 ng/mL for patients aged 21-25, 26-30, 31-35, 36-40, 41-45, 46-50, 51-55, 56-60, 61-65 and 66-70, respectively), IGFBP-3 (3.4-7.8, 3.5-7.6, 3.5-7.0, 3.4-6.7, 3.4-6.6, 3.3-6.7, 3.4-6.8, 3.4-6.9, 3.2-6.6, 3.0-6.2 mcg/mL for patients aged 21-25, 26-30, 31-35, 36-40, 41-45, 46-50, 51-55, 56-60, 61-65 and 66-70, respectively), PRL (2.1-17.7 ng/mL), FSH (1.4-18.1 mUl/mL), LH (1.5-9.3 mUl/mL), total testosterone (241-827 ng/dL), free testosterone (4.7-23 ng/dL), bioavailable testosterone (140-400 ng/dL), SHBG (13-71 nmol/L), total PSA (less than $4 \mathrm{ng} / \mathrm{mL}$ ), free PSA (less than $0.92 \mathrm{ng} / \mathrm{mL}$ ), IPSS (0-35), prostate volume (less than $30 \mathrm{~mL}$ ).

in five patients, two of them under 40 years, and the four patients initially considered cured/controlled at baseline, persisted with cure/control criteria. The inclusion of these four patients did not influence the outcomes of the research. No significant reduction in PV was observed after treatment (18.50 vs 18.50 , $\mathrm{p}=0.75)$ and there was no significant difference in the frequency of prostate hyperplasia ( $0 \%$ vs $7.14 \%$, $\mathrm{p}=0.50$ ) neither in the frequency of structural $a b-$ normalities found at transrectal US. The reduction in IPSS achieved borderline statistical significance (2.00 vs $2.00, \mathrm{p}=0.056$ ).

Comparison of the acromegalic patients above 40 years at baseline and after one year of treatment The main characteristics of the study population above 40 years before and after treatment are presented in Table- 4 . 
Table 3 - Characteristics of acromegalic patients at baseline and after one year of treatment ( $<40$ years-old).

\begin{tabular}{|c|c|c|c|c|c|}
\hline & \multicolumn{2}{|c|}{$\begin{array}{l}\text { Baseline } \\
(\mathrm{n}=14)\end{array}$} & \multicolumn{2}{|c|}{$\begin{array}{c}1 \text { year } \\
(n=14)\end{array}$} & \multirow[t]{2}{*}{$\mathrm{p}$ value } \\
\hline & Median & Min-Max & Median & Min-Max & \\
\hline $\mathrm{GH}(\mathrm{ng} / \mathrm{mL})$ & 4.96 & $0.23-40.00$ & 3.28 & $0.21-20.30$ & 0.011 \\
\hline IGF-I (ng/mL) & 914.50 & $114.00-1158.00$ & 522.50 & $131.00-1345.00$ & 0.133 \\
\hline IGFBP-3 (mcg/mL) & 6.96 & $1.96-10.50$ & 6.72 & $3.33-9.26$ & 0.638 \\
\hline PRL (ng/mL) & 9.00 & $0.50-61.00$ & 9.70 & $0.30-85.59$ & 0.363 \\
\hline $\mathrm{FSH}(\mathrm{mUl} / \mathrm{mL})$ & 4.86 & $0.10-14.70$ & 2.95 & $0.30-10.50$ & 0.013 \\
\hline $\mathrm{LH}(\mathrm{mUl} / \mathrm{mL})$ & 2.07 & $0.10-6.97$ & 1.23 & $0.07-6.95$ & 0.03 \\
\hline Total testosterone (ng/dL) & 135.00 & $20.00-289.00$ & 170.00 & $31.00-424.00$ & 0.079 \\
\hline Free testosterone $(\mathrm{ng} / \mathrm{dL})$ & 4.16 & $0.73-7.44$ & 5.14 & $1.10-12.80$ & 0.035 \\
\hline Bioavailable testosterone (ng/dL) & 97.00 & $17.10-174.00$ & 120.50 & $25.70-301.00$ & 0.035 \\
\hline SHBG (nmol/L) & 11.00 & $3.60-35.90$ & 12.00 & $5.00-28.30$ & 0.47 \\
\hline Total PSA (ng/mL) & 0.65 & $0.04-1.65$ & 0.48 & $0.01-2.27$ & 0.28 \\
\hline Free PSA (ng/mL) & 0.12 & $0.05-0.38$ & 0.16 & $0.01-0.41$ & 0.78 \\
\hline IPSS & 2.00 & $0.00-12.00$ & 2.00 & $0.00-6.00$ & 0.056 \\
\hline Prostate volume $(\mathrm{mL})$ & 18.50 & $12.00-28.00$ & 18.50 & $11.00-32.00$ & 0.753 \\
\hline
\end{tabular}

Normal Values: GH (0.06-5 ng/mL), IGF-I (116-358, 117-329, 115-307, 109-284, 101-267, 94-252, 87-238, 81-225, 75-212, 69-200 ng/mL for patients aged 21-25, 26-30, 31-35, 36-40, 41-45, 46-50, 51-55, 56-60, 61-65 and 66-70, respectively), IGFBP-3 (3.4-7.8, 3.5-7.6, 3.5-7.0, 3.4-6.7, 3.4-6.6, 3.3-6.7, 3.4-6.8, 3.4-6.9, 3.2-6.6, 3.0-6.2 mcg/mL for patients aged 21-25, 26-30, 31-35, 36-40, 41-45, 46-50, 51-55, 56-60, 61-65 and 66-70, respectively), PRL (2.1-17.7 ng/mL), FSH (1.4-18.1 mUl/mL), LH (1.5-9.3 mUl/mL), total testosterone (241-827 ng/dL), free testosterone (4.7-23 ng/dL), bioavailable testosterone (140-400 ng/dL), SHBG (13-71 nmol/L), total PSA (less than $4 \mathrm{ng} / \mathrm{mL}$ ), free PSA (less than $0.92 \mathrm{ng} / \mathrm{mL}$ ), IPSS (0-35), prostate volume (less than $30 \mathrm{~mL}$ ).

After one year of treatment, there was a significant reduction in $\mathrm{GH}(4.92$ vs $1.85, \mathrm{p}=0.015)$ and IGF-I (466.00 vs 362.50, $\mathrm{p}=0.020$ ) levels. Significant reduction in PV was observed after treatment ( 28.50 vs $25.50, p=0.001$ ), however there was no significant difference in the frequency of prostate hyperplasia ( $46.15 \%$ vs $30.76 \%, \mathrm{p}=0.43$ ) neither in the frequency of structural abnormalities found at transrectal US. There was no reduction in IPSS (4.50 vs $4.50, \mathrm{p}=0.65$ ).
The findings of digital rectal examination, both in acromegalics under and above 40 years, were in accordance with transrectal US.

\section{DISCUSSION}

There are three important studies in the literature, all of them European, reporting the prevalence of benign prostate hyperplasia and structural abnormalities in acromegalic patients 
Table 4 - Characteristics of acromegalic patients at baseline and after one year of treatment ( $\geq \mathbf{4 0}$ years-old).

\begin{tabular}{lccccc}
\hline & & $\begin{array}{l}\text { Baseline } \\
(\mathrm{n}=26)\end{array}$ & \multicolumn{1}{c}{$\begin{array}{c}\text { year } \\
(\mathrm{n}=26)\end{array}$} & $p$ value \\
& Median & Min-Max & Median & Min-Max & \\
\hline GH (ng/mL) & 4.92 & $0.28-68.90$ & 1.85 & $0.16-68.40$ & 0.015 \\
IGF-I (ng/mL) & 466.00 & $104.00-1600.00$ & 362.50 & $129.00-959.00$ & 0.020 \\
IGFBP-3 (mcg/mL) & 5.65 & $3.24-11.90$ & 5.36 & $2.33-9.09$ & 0.131 \\
PRL (ng/mL) & 5.82 & $0.50-86.39$ & 5.16 & $0.20-43.87$ & 0.135 \\
FSH (mUl/mL) & 4.06 & $0.10-15.40$ & 3.65 & $0.10-17.40$ & 0.367 \\
LH (mUl/mL) & 1.81 & $0.10-4.68$ & 2.53 & $0.07-6.30$ & 0.191 \\
Total testosterone (ng/dL) & 256.50 & $20.00-1688.00$ & 252.00 & $14.00-661.00$ & 0.751 \\
Free testosterone (ng/dL) & 5.95 & $0.23-66.90$ & 6.05 & $0.18-12.00$ & 0.568 \\
Bioavailable testosterone (ng/dL) & 139.50 & $5.39-1570.00$ & 142.00 & $4.15-281.00$ & 0.568 \\
SHBG (nmol/L) & 20.40 & $6.00-79.50$ & 20.00 & $9.00-63.20$ & 0.696 \\
Total PSA (ng/mL) & 0.63 & $0.04-2.50$ & 0.93 & $0.03-3.91$ & 0.049 \\
Free PSA (ng/mL) & 0.15 & $0.04-0.57$ & 0.18 & $0.01-0.54$ & 0.501 \\
IPSS & 4.50 & $0.00-21.00$ & 4.50 & $0.00-25.00$ & 0.649 \\
Prostate volume (mL) & 28.50 & $10.00-84.00$ & 25.50 & $12.00-69.00$ & 0.001 \\
\hline
\end{tabular}

Normal Values: GH (0.06-5 ng/mL), IGF-I (116-358, 117-329, 115-307, 109-284, 101-267, 94-252, 87-238, 81-225, 75-212, 69-200 ng/mL for patients aged 21-25, 26-30, 31-35, 36-40, 41-45, 46-50, 51-55, 56-60, 61-65 and 66-70, respectively), IGFBP-3 (3.4-7.8, 3.5-7.6, 3.5-7.0, 3.4-6.7, 3.4-6.6, 3.3-6.7, 3.4-6.8, 3.4-6.9, 3.2-6.6, 3.0-6.2 mcg/mL for patients aged 21-25, 26-30, 31-35, 36-40, 41-45, 46-50, 51-55, 5660, 61-65 and 66-70, respectively), PRL (2.1-17.7 ng/mL), FSH (1.4-18.1 mUl/mL), LH (1.5-9.3 mUl/mL), total testosterone (241-827 ng/dL), free testosterone (4.7-23 ng/dL), bioavailable testosterone (140-400 ng/dL), SHBG (13-71 nmol/L), total PSA (less than $4 \mathrm{ng} / \mathrm{mL}$ ), free PSA (lass than $0.92 \mathrm{ng} / \mathrm{mL}$ ), IPSS (0-35), prostate volume (lass than $30 \mathrm{~mL}$ ).

(10-12). Two of these studies compared acromegalics to age-matched healthy subjects $(10,11)$. Until today, there is no report of the use of IPSS in the evaluation of acromegalic patients.

Although physiological development and growth of the prostate depend on testosterone and dihydrotestosterone (DHT), androgens action alone seems to be insufficient to explain prostatic diseases $(22,25)$. The existence of important cross-talk among androgens, growth factors and IGF binding proteins at prostatic level has been suggested (26). Patients with acromegaly are an interesting population model to study the possible involvement of IGF-I in the development of prostatic diseases. In our study, the group of acromegalic patients above 40 years presented a higher proportion of $\mathrm{BPH}$ (46.15 vs $12.50 \%$ ) and structural prostatic changes, such as calcifications and corpora amylacea, when 
compared to age-matched healthy men. Colao et al., in a study that included 30 acromegalics with active disease and a control group, demonstrated that the prevalence of BPH was significantly higher in the group of acromegalics (58\% vs $26.6 \%$ ) and structural abnormalities were shown in a large proportion of these patients (11). Probably, we found less prostate hyperplasia than Colao's group because our patients were younger. Nonetheless, these data suggest a possible role of GH-IGF-I axis on prostate growth.

Only one study evaluated the effects of acromegaly treatment on prostatic disorders (12). This study included 23 acromegalics and evaluated PV and structural prostatic abnormalities before and after two years of acromegaly treatment with surgery and/or lanreotide. Considering the whole group of patients, there was no significant change in PV after two years of treatment (34.6 vs 32.5 $\mathrm{mL}, \mathrm{p}=0.3$ ). However, when analyzing only well controlled patients $(\mathrm{n}=16)$, there was a significant reduction in PV (29.3 vs $25.4 \mathrm{~mL}, \mathrm{p}=0.03$ ). Regarding the eleven patients that presented $\mathrm{BPH}$ at baseline, four had PV $<30 \mathrm{~mL}$ at the end of the 2-year follow-up, all of them with controlled acromegaly. In our study, when we analyzed the acromegalics above 40 years, there was a significant reduction in the PV after one year of treatment ( 28.50 vs 25.50 $\mathrm{mL}, \mathrm{p}=0.001$ ), independently of disease control. Of the twelve patients that had BPH at baseline, five presented $\mathrm{PV}<30 \mathrm{~mL}$ at the end of the study and only one of them had the disease controlled. This finding suggests that a significant reduction in $\mathrm{GH}$ and IGF-I levels is sufficient to promote reversion of $\mathrm{BPH}$, even though biochemical criteria of acromegaly control was not achieved.

It is well established that prostate enlargement starts approximately at the age of 40 (22). In a community-based group of 502 men aged 55 to 74 years without prostate cancer, the prevalence of $\mathrm{BPH}$ was $19 \%$ using the criteria of a PV above 30 $\mathrm{mL}$ together with a high IPSS score (15). Berry et al. (19) described that the PV in men aged 21 to 30 years is approximately $20 \pm 6 \mathrm{~mL}$. Analyzing our patients according to age, 14 (35\%) were younger than 40 years-old and prostate hyperplasia was not found at baseline. Five out of 12 patients with prostate hyperplasia (41.6\%) were aged from 40 to 50 years-old. Besides, our data shows that PV in acromegalics and the control group younger than 40 years-old is not different, however, IPSS score in the acromegalics is higher than in the control group. In contrast, probably there was no difference in IPSS score in acromegalics and the control group older than 40 years-old because at this age both groups are already exposed to the onset of urinary symptoms. This is the first report of the use of IPSS in the evaluation of acromegalic patients.

\section{CONCLUSIONS}

This was the first Brazilian study that assessed prostate disorders in patients with acromegaly. We demonstrated that acromegalic patients above 40 years-old have a higher frequency of structural changes and increased prostate volume in comparison to age-matched healthy men. In this group, significant reduction of GH and IGF-I levels during treatment of acromegaly leads to decrease in the prostate volume.

\section{ABBREVIATIONS}

AUA $=$ American Urological Association

BPH = Benign Prostate Hyperplasia

DHT $=$ Dihydrotestosterone

DPC $=$ Diagnostic Products Corporation

FSH $=$ Follicle-Stimulating Hormone

$\mathrm{GH}=$ Growth Hormone

HUCFF = Hospital Universitário Clementino Fraga Filho

IGF-I = Insulin-Like Growth Factor-I

IGFBP-3 = Insulin-Like Growth Factor-Binding Protein-3

IPSS = International Prostatic Symptoms Score

LH = Luteinizing Hormone

PSA = Prostate-Specific Antigen

$\mathrm{PV}=$ Prostate Volume

SHBG = Sex Hormone-Binding Globulin

UFRJ = Universidade Federal do Rio de Janeiro

US = Ultrasonography

\section{ACKNOWLEDGMENTS}

We are deeply indebted to Isabel Pessoa and Rosita Fontes, Laboratório Diagnósticos da América - Medicina Diagnóstica, for the measurements of IGF-I, IGFBP-3, SHBG, total and free PSA 


\section{CONFLICT OF INTEREST}

None declared.

\section{REFERENCES}

1. Melmed S: Acromegaly. N Engl J Med. 1990; 322: 966-77.

2. Taboada GF, van Haute FR, Corrêa LL, Casini AF, Gadelha MR: Etiologic aspects and management of acromegaly. Arq Bras Endocrinol Metabol. 2005; 49: 626-40.

3. Qu BH, Karas M, Koval A, LeRoith D: Insulin receptor substrate-4 enhances insulin-like growth factor--induced cell proliferation. J Biol Chem. 1999; 274: 31179-84.

4. Butt AJ, Firth SM, Baxter RC: The IGF axis and programmed cell death. Immunol Cell Biol. 1999; 77: 256-62.

5. Chan JM, Stampfer MJ, Giovannucci E, Gann PH, Ma J, Wilkinson $P$, et al.: Plasma insulin-like growth factor-I and prostate cancer risk: a prospective study. Science. 1998; 279: 563-6.

6. Wolk A, Mantzoros CS, Andersson SO, Bergström R, Signorello $L B$, Lagiou $P$, et al.: Insulin-like growth factor 1 and prostate cancer risk: a population-based, case-control study. J Natl Cancer Inst. 1998; 90: 911-5.

7. Mantzoros CS, Tzonou A, Signorello LB, Stampfer M, Trichopoulos D, Adami HO: Insulin-like growth factor 1 in relation to prostate cancer and benign prostatic hyperplasia. $\mathrm{Br} \mathrm{J}$ Cancer. 1997; 76: 1115-8.

8. Renehan AG, Zwahlen M, Minder C, O'Dwyer ST, Shalet SM, Egger M: Insulin-like growth factor (IGF)-I, IGF binding protein-3, and cancer risk: systematic review and meta-regression analysis. Lancet. 2004; 363: 1346-53.

9. Jenkins PJ, Besser M: Clinical perspective: acromegaly and cancer: a problem. J Clin Endocrinol Metab. 2001; 86: 2935-41.

10. Colao A, Marzullo P, Ferone D, Spiezia S, Cerbone G, Marinò $\mathrm{V}$, et al:: Prostatic hyperplasia: an unknown feature of acromegaly. J Clin Endocrinol Metab. 1998; 83: 775-9.

11. Colao A, Marzullo P, Spiezia S, Ferone D, Giaccio A, Cerbone $G$, et al.: Effect of growth hormone (GH) and insulin-like growth factor I on prostate diseases: an ultrasonographic and endocrine study in acromegaly, GH deficiency, and healthy subjects. J Clin Endocrinol Metab. 1999; 84: 1986-91.

12. Colao A, Marzullo P, Spiezia S, Giaccio A, Ferone D, Cerbone $G$, et al.: Effect of two years of growth hormone and insulinlike growth factor-I suppression on prostate diseases in acromegalic patients. J Clin Endocrinol Metab. 2000; 85: 3754-61.

13. Barry MJ, Fowler FJ Jr, O'Leary MP, Bruskewitz RC, Holtgrewe HL, Mebust WK, et al.: The American Urological Association symptom index for benign prostatic hyperplasia. The Measurement Committee of the American Urological Association. J Urol. 1992; 148: 1549-57; discussion 1564.
14. Suaid $\mathrm{HJ}$, Gonçalves MA, Rodrigues AA Jr, Cunha JP, Cologna AJ, Martins AC: Estimated costs of treatment of benign prostate hyperplasia in Brazil. Int Braz J Urol. 2003; 29: 234-7.

15. Bosch JL, Hop WC, Kirkels WJ, Schröder FH: The International Prostate Symptom Score in a community-based sample of men between 55 and 74 years of age: prevalence and correlation of symptoms with age, prostate volume, flow rate and residual urine volume. Br J Urol. 1995; 75: 622-30.

16. Melmed S, Colao A, Barkan A, Molitch M, Grossman AB, Kleinberg $D$, et al.: Guidelines for acromegaly management: an update. J Clin Endocrinol Metab. 2009; 94: 1509-17.

17. Vermeulen A, Verdonck L, Kaufman JM: A critical evaluation of simple methods for the estimation of free testosterone in serum. J Clin Endocrinol Metab. 1999; 84: 3666-72.

18. Berger M, Luz Junior PN, Silva Neto B, Koff WJ: Statistical validation of the international prostatic symptom score (I-PSS) in portuguese. J Bras Urol. 1999; 25:225-34.

19. Berry SJ, Coffey DS, Walsh PC, Ewing LL: The development of human benign prostatic hyperplasia with age. J Urol. 1984; 132: 474-9.

20. Collins GN, Raab GM, Hehir M, King B, Garraway WM: Reproducibility and observer variability of transrectal ultrasound measurements of prostatic volume. Ultrasound Med Biol. 1995; 21: 1101-5.

21. McNeal JE: Normal histology of the prostate. Am J Surg Pathol. 1988; 12: 619-33.

22. Wilson JD: The pathogenesis of benign prostatic hyperplasia. Am J Med. 1980; 68: 745-56.

23. Lepor $\mathrm{H}$ : Pathophysiology, epidemiology, and natural history of benign prostatic hyperplasia. Rev Urol. 2004; 6(Suppl 9): S3-S10.

24. Giustina A, Chanson P, Bronstein MD, Klibanski A, Lamberts $\mathrm{S}$, Casanueva FF, et al.: A consensus on criteria for cure of acromegaly. J Clin Endocrinol Metab. 2010; 95: 3141-8.

25. Cunha GR, Donjacour AA, Cooke PS, Mee S, Bigsby RM, Higgins SJ, et al.: The endocrinology and developmental biology of the prostate. Endocr Rev. 1987; 8: 338-62.

26. Motta M, Dondi D, Moretti RM, Montagnani Marelli M, Pimpinelli $F$, Maggi $R$, et al.: Role of growth factors, steroid and peptide hormones in the regulation of human prostatic tumor growth. J Steroid Biochem Mol Biol. 1996; 56: 107-11.

\footnotetext{
Correspondence address:

Dr. Lívia Lugarinho Corrêa de Mello Avenida General San Martin, 900 / 603, Leblon Rio de Janeiro, RJ, 22441-014, Brazil Fax: + 5521 2421-5335 E-mail: livia.lugarinho@terra.com.br
} 